ARTICLE

Received 28 May 2013 | Accepted 16 Jan 2014 | Published 7 Feb 2014

DOI: $10.1038 /$ ncomms 4271

OPEN

\title{
Large mesopelagic fishes biomass and trophic efficiency in the open ocean
}

Xabier Irigoien', T.A. Klevjer'1, A. Røstad', U. Martinez², G. Boyra², J.L. Acuña ${ }^{3}$, A. Bode ${ }^{4}$, F. Echevarria ${ }^{5}$, J.I. Gonzalez-Gordillo ${ }^{5}$, S. Hernandez-Leon ${ }^{6}$, S. Agusti7,8, D.L. Aksnes ${ }^{9}$, C.M. Duarte ${ }^{7,8}$ \& S. Kaartvedt ${ }^{1}$

With a current estimate of $\sim 1,000$ million tons, mesopelagic fishes likely dominate the world total fishes biomass. However, recent acoustic observations show that mesopelagic fishes biomass could be significantly larger than the current estimate. Here we combine modelling and a sensitivity analysis of the acoustic observations from the Malaspina 2010 Circumnavigation Expedition to show that the previous estimate needs to be revised to at least one order of magnitude higher. We show that there is a close relationship between the open ocean fishes biomass and primary production, and that the energy transfer efficiency from phytoplankton to mesopelagic fishes in the open ocean is higher than what is typically assumed. Our results indicate that the role of mesopelagic fishes in oceanic ecosystems and global ocean biogeochemical cycles needs to be revised as they may be respiring $\sim 10 \%$ of the primary production in deep waters.

\footnotetext{
${ }^{1}$ King Abdullah University of Science and Technology (KAUST), Red Sea Research Center, Thuwal 23955-6900, Saudi Arabia. ${ }^{2}$ AZTI, Arrantza eta Elikaigintzarako Institutu Teknologikoa, Herrera Kaia Portualdea, 20110 Pasaia, Spain. ${ }^{3}$ Departamento de Biología de Organismos y Sistemas, Universidad de Oviedo, Calle Catedrático Rodrigo Uría, Sin Número, 33071 Oviedo, Spain. ${ }^{4}$ Instituto Español de Oceanografía (IEO), Centro Oceanográfico de A Coruña, Apdo 130, E15080 A Coruña, Spain. ${ }^{5}$ Departamento de Biología, Facultad de Ciencias del Mar y Ambientales, Universidad de Cádiz, Campus de Excelencia Internacional del Mar (CEl - MAR), E-11510 Puerto Real, Spain. ${ }^{6}$ Institute of Oceanography and Global Change, Universidad de Las Palmas de Gran Canaria, Campus Universitario de Tafira, Las Palmas de Gran Canaria, 35017 Canary Islands, Spain. 7 The UWA Oceans Institute and School of Plant Biology, University of Western Australia, 35 Stirling Highway, Crawley, Western Australia 6009, Australia. ${ }^{8}$ Department of Global Change Research, IMEDEA (UIB-CSIC), Instituto Mediterráneo de Estudios Avanzados, Esporles 07190, Spain. ${ }^{9}$ Department of Biology, University of Bergen, Bergen N-5020, Norway.

Correspondence and requests for materials should be addressed to X.I. (email: Xabier.irigoyen@kaust.edu.sa).
} 
M esopelagic fishes-the small fishes living in the ocean's twilight zone-form one of the most characteristic features of the open ocean: the deep scattering layer at depths between 200 and $1,000 \mathrm{~m}$, visible in the echosounder display of vessels sailing all oceans ${ }^{1}$. Whereas the mesopelagic fish genus Cyclothone sp. is likely the most abundant vertebrate on earth $^{2}$, mesopelagic fishes remain one of the least investigated components of the open-ocean ecosystem, with major gaps in our knowledge of their biology and adaptations, and even major uncertainties about their global biomass. Trawling estimates suggest that the biomass of mesopelagic fishes is $\sim 1,000$ million tons ${ }^{3,4}$, a number commonly used in assessments of ecosystem function and the biogeochemistry of the global ocean ${ }^{5,6}$. However, even for the original estimate it was stated that 'most of the gear used to obtain the available information obviously underestimate the biomass present ${ }^{3}$, and the efficiency of different types of nets to capture mesopelagic organisms has been further questioned recently, with inter-calibration exercises showing order-of-magnitude differences in the captured biomass depending on the type of gear ${ }^{7}$. Moreover, trawling-based biomass estimates are systematically below acoustic estimates ${ }^{7-9}$, as mesopelagic fishes have been shown to exhibit escape reactions to nets, rendering trawling data suspect of gross underestimation ${ }^{10}$.

Here we combine a sensitivity analysis of acoustic data collected during Malaspina 2010, the Spanish Circumnavigation Expedition (December 2010-July 2011, Fig. 1a), and modelling, to show that mesopelagic fishes biomass in the open ocean is about one order of magnitude higher than previous estimates. We furthermore examine the mesopelagic fishes biomass relative to primary production (PP) and consider the implications of these estimates for the functioning of the open-ocean ecosystem and biogeochemical cycles.

\section{Results}

Acoustic biomass estimates. A Simrad EK60 echosounder operating at $38 \mathrm{kHz}$ frequency was used to obtain data throughout the 32,000-mile voyage (Fig. 1a). We used data obtained during the daytime from $200-1,000 \mathrm{~m}$ depths, comprising the main diurnal habitat of mesopelagic fishes, to calculate fish biomass and considering the different sources of uncertainties involved (Methods). The average ( \pm s.d.) nautical area scattering coefficient $\left(s_{\mathrm{A}}, \mathrm{m}^{2} \mathrm{nmi}^{-2}\right)$ in the 200-1,000 m layer for the whole cruise was $1,864 \pm 1,341$, with individual estimates ranging from $158-7,617 \mathrm{~m}^{2} \mathrm{n} \mathrm{mi}^{-2} \quad\left(N=209\right.$, Fig. 1a,b). The $s_{\mathrm{A}}$ was significantly correlated with the 2010 satellite-derived average daily PP $\left(\mathrm{mg} \mathrm{C} \mathrm{m}^{-2} \mathrm{~d}^{-1}\right)^{11}$, (Fig. 2, Pearson's $r=0.77$, F corrected for spatial autocorrelation $=26$, D.F. corrected for spatial autocorrelation $=18, \quad P<0.01)$. This relation shows heteroscedasticity (Supplementary Fig. 1) and because of the cruise design (from coast to coast at similar distances) it also shows spatial autocorrelation at different spatial scales (Moran I test, Supplementary Fig. 2) ${ }^{12}$. Therefore, we used a geographically weighted regression $(\mathrm{GWR})^{13}$ on $\ln$-transformed values to parameterize the relationships between $\mathrm{PP}$ and $s_{\mathrm{A}}$ through regression analysis (Methods). The GWR was significant in $96 \%$ of the sampling points, ranging from oceanic gyres to near shelf areas (Supplementary Fig. 3). The only area where the GWR was not significant was in the vicinity of the Humboldt upwelling system where the water column was severely hypoxic below $100 \mathrm{~m}$ (Supplementary Fig. 4).

We used the equations obtained through the GWR in two ways to derive estimates of the $s_{\mathrm{A}}$ from satellite-estimated PP: first, the median values of all the GWR parameters and second, as the regression parameters above $400 \mathrm{mg} \mathrm{C} \mathrm{m}^{-2} \mathrm{~d}^{-1}$ of PP show less variability (Supplementary Fig. 5), we also considered different equations with the median values for data below and above $400 \mathrm{mg} \mathrm{C} \mathrm{m}^{-2} \mathrm{~d}^{-1}$ (Supplementary Table 1). Use of the relation between PP and $s_{\mathrm{A}}$ (Fig. 2), together with the distribution of PP, to integrate mesopelagic fishes biomass for areas with bottom depths deeper than $1,000 \mathrm{~m}$ between $40^{\circ} \mathrm{N}$ and $40^{\circ} \mathrm{S}$ (the latitudinal range covered by the Malaspina expedition, Fig. 1a) yielded a total $s_{\mathrm{A}}$ of $5.6 \times 10^{17}$ (Table 1 ).

We transformed the backscattering strength integrated over the 200-1,000 m layer, $s_{\mathrm{A}}$, into mesopelagic fishes biomass using $\mathrm{db} /$ weight ratios derived from the literature (Table 2 ). To account for the variability in these ratios we considered the minimum, maximum, average, median, 25 and $75 \%$ quartiles of the literature values. Table 1 presents the range of mesopelagic fishes biomass obtained using different approaches to estimate the total $s_{\mathrm{A}}$ between $40^{\circ} \mathrm{N}$ and $40^{\circ} \mathrm{S}$ (ordinary least squares regression, GWR, average $s_{\mathrm{A}}$ from the cruise) and $\mathrm{db} /$ weight ratios. We found that total mesopelagic fishes biomass was robust against different approaches to estimate $s_{\mathrm{A}}$ with a difference of $25 \%$ between the maximum (GWR) and the minimum (cruise average). If we consider the range between 25 and $75 \%$ quartiles of the literature $\mathrm{db} /$ weight ratios as a reasonable representation of the mesopelagic fishes around the world, our estimates of mesopelagic fishes biomass would range from 6,000-200,000 million tons, with median values between 11,000 and 15,000 million tons (Table 1). These estimates of mesopelagic fishes biomass limited to $40^{\circ} \mathrm{N}$ and $40^{\circ} \mathrm{S}$ are one order of magnitude higher than the previous global estimate of 1,000 million tons $s^{3,4}$.

As mesopelagic fishes are not the only source of backscatter we conducted a sensitivity analysis to understand which combinations of $\mathrm{db}$ /weight ratios and fraction of the backscatter coming from fishes would result in the present day estimate of 1,000 million tons. Figure 3 shows that the present day estimate can only be attained if all mesopelagic fishes populations had a $\mathrm{db} /$ weight ratio close to the maximum observed in the literature and mesopelagic fishes represented $<20 \%$ of backscatter or if they were $<10 \%$ of the backscatter for a wider distribution of $\mathrm{db} /$ weight values (Fig. 3). Any contribution to the backscatter higher than $20 \%$, as generally reported ${ }^{9,14}$, results in a biomass several times higher than the one accepted (Fig. 3).

Modelling biomass estimates. Global fishes biomass estimates derived from food web models are typically between 900 and 2,000 million tons ${ }^{15-17}$, about 10 -fold below our direct, acoustic measurement. In some of those models, the mesopelagic biomass is an input affecting total fishes biomass estimates ${ }^{15}$; in others the final value is very sensitive to the transfer efficiency used ${ }^{16}$, and finally, the most recent work by Tremblay-Boyer et al. ${ }^{17}$ using ECOTROPH ${ }^{18}$ derived its estimate of fishes biomass assuming that $10 \%$ of the $\mathrm{PP}$ was transferred from $\mathrm{PP}$ to herbivores (Gascuel pers. comm.). This value of $10 \%$ corresponds to the consumption of PP by mesozooplankton in productive areas (mainly copepods) ${ }^{19}$. Yet, ample evidence shows that microzooplankton, not mesozooplankton, are the major consumers of $\mathrm{PP}$, consuming $70-80 \%$ of the PP on average $\mathrm{e}^{20}$. The percentage of the PP consumed by mesozooplankton in the less productive oceanic waters is also more likely to be $\sim 20 \%$ rather than $10 \%$ (ref. 19). Therefore, if we consider micro and mesozooplankton together the percentage of PP entering the food web should be closer to $90 \%$. Hence, we have run the ECOTROPH model with a generic open-ocean ecosystem model using the average $\mathrm{PP}$ for the area between $40^{\circ} \mathrm{N}$ and $40^{\circ} \mathrm{S}\left(344 \mathrm{mg} \mathrm{C} \mathrm{m}^{-2} \mathrm{~d}^{-1}\right)$ and considering a flux from PP to the trophic web of 70, 80 and $90 \%$, with transfer efficiencies between trophic levels ranging from 0.05 to 0.2 (ref. 21) and an average temperature of $9^{\circ} \mathrm{C}$. Results, shown in Table 3, range from 2,000-70,000 million tones. 
a
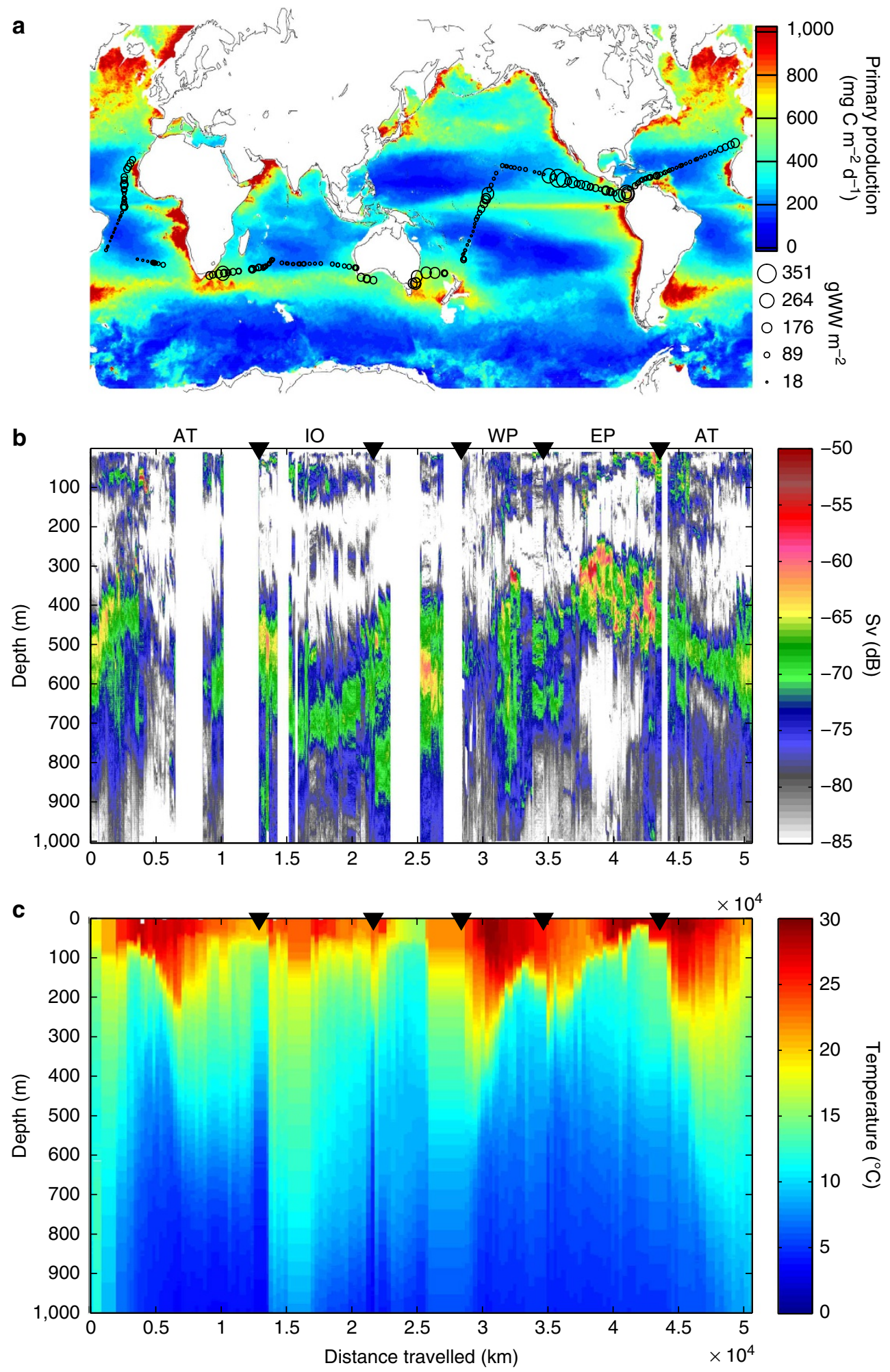

Figure 1 | The Malaspina cruise. (a) The surface-integrated estimated mesopelagic fishes biomass ( $\mathrm{g}$ wet weight per $\mathrm{m}^{2}$ ) for the 200-1,000 $\mathrm{m}$ depth range along the Malaspina 2010 Expedition cruise transect (black circles) superimposed on a satellite-derived global map of PP (average in $\mathrm{mg} \mathrm{C} \mathrm{m}{ }^{-2} \mathrm{~d}^{-1}$ for 2010-colour bar); (b) a daytime echogram from 0-1,000 $\mathrm{m}$ along the cruise track (measured in $\mathrm{dB}-$ colour bar), and (c) interpolated temperature profiles along the cruise track (measured in ${ }^{\circ} \mathrm{C}$-colour bar). The black triangles in $\mathbf{b}$ and $\mathbf{c}$ indicate the border between oceanic basins. AT for Atlantic Ocean, IO for Indian Ocean, WP for Western Pacific and EP for Eastern Pacific.

Both along the Malaspina transect (Fig. 4) and in the global estimate (Table 3), the modelled biomasses using ECOTROPH with a transfer efficiency of $10 \%$ fall within the range of acoustic estimates using the median $\mathrm{db} /$ weight ratio (10-15,000 million tons).
Production and transfer efficiency. We estimated mesopelagic fishes production (MFP) considering equations relating fishes production/biomass $(\mathrm{P} / \mathrm{B})$ ratios to the trophic level, assumed to be 3.2 for mesopelagic fishes (www.Fishbase.org) and 
temperature ${ }^{22}$, which was derived from temperature profiles weighted by the depth distribution of the fishes biomass (Fig. 1b,c). This resulted in an average $\mathrm{P} / \mathrm{B}$ for mesopelagic fishes of 0.5 (average \pm s.d. $0.51 \pm 0.05$ ). Biomass was estimated in a conservative way using the median and $75 \%$ quartile of the literature $\mathrm{db}$ /weight ratios. As the mean-weighted temperature in the deep layers was relatively uniform (average $9^{\circ} \mathrm{C}$, range $6^{\circ} \mathrm{C}$ to $13^{\circ} \mathrm{C}$, Fig. 1c), we found that MFP was also significantly correlated to PP (Pearson's $r=0.68, \mathrm{~F}$ corrected for spatial autocorrelation $=21$, D.F. corrected for spatial autocorrelation $=26, P<0.01)$. The average MFP values calculated along the Malaspina 2010 transect ranged between 16 and $27 \mathrm{~g} \mathrm{~m}^{-2} \mathrm{y}^{-1} \quad$ (average \pm s.d. $\quad$ MFP $=27.2 \pm 20.1$ and $15.6 \pm 11.6 \mathrm{~g} \mathrm{~m}^{-2} \mathrm{y}^{-1}$ for median and $75 \%$ quartile $\mathrm{db} /$ weight ratios). The corresponding average transfer efficiency from PP (TL1) to MFP (TL3) was 0.02 (average \pm s.d. MFP/PP ratio $=0.022 \pm 0.013$ ) when using the median $\mathrm{db} /$ weight ratio and 0.01 when using the $75 \%$ quartile (average \pm s.d. MFP/PP ratio $=0.013 \pm 0.008$ ) (Fig. 5).

\section{Discussion}

Through the use of acoustic data deeper than $200 \mathrm{~m}$ and considering the open-ocean areas between $40^{\circ} \mathrm{N}$ and $40^{\circ} \mathrm{S}$ with bottom depth deeper than $1,000 \mathrm{~m}$ and trophic levels $3-3.5$ this analysis focuses on mesopelagic fishes, excluding fishes living in shelf areas, epipelagic fishes and higher-level predator fishes in

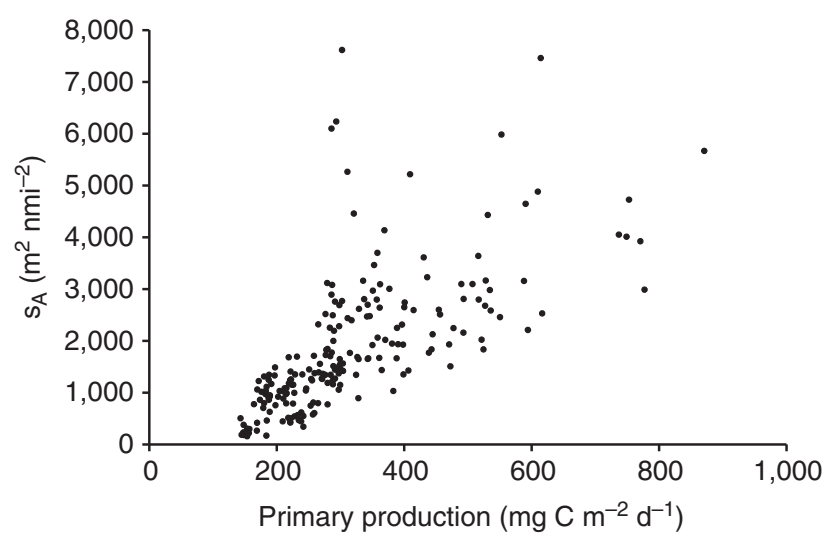

Figure 2 | Relationship between PP and acoustic backscatter. The relationship between PP (2010 annual average $\mathrm{mg} \mathrm{C}^{-2} \mathrm{~d}^{-1}$ ) and the nautical area scattering coefficient $\left(s_{A}, m^{2} \mathrm{nmi}^{-2}\right)$ from $200-1,000 \mathrm{~m}$ during day time. the open ocean. Our results indicate that the mesopelagic fishes biomass in the global ocean is much higher than the previous estimate of 1,000 million tons ${ }^{3,4}$. The sensitivity analysis (Fig. 3) indicates that a better knowledge of the composition and acoustic properties of the mesopelagic community is needed to obtain accurate estimates of the biomass. However, considering the agreement between the acoustic estimate using the median $\mathrm{db} /$ weight value and the model using $10 \%$ efficiency between trophic levels we suggest that the most likely estimate of mesopelagic fishes biomass between $40^{\circ} \mathrm{N}$ and $40^{\circ} \mathrm{S}$ is at least an order of magnitude higher than the previous estimate of 1,000 million tons. Our analysis is limited to the latitudinal range covered by the Malaspina expedition $\left(40^{\circ} \mathrm{N}-40^{\circ} \mathrm{S}\right)$. Yet, mesopelagic fish are also abundant in higher latitudes, although their abundance strongly decreases in polar waters. Considering only the surface of the area the estimate could be $\sim 30 \%$ higher if expanded to the deep ocean between $70^{\circ} \mathrm{N}$ and $70^{\circ} \mathrm{S}$. Actually, the biomass levels we find using acoustics and the median $\mathrm{db} /$ weight, as well as the relation between PP and mesopelagic fishes biomass, agree well with recent observations in the northeast Pacific Ocean ${ }^{23}$. Both our estimate using acoustics and the local estimates in the northeast Pacific Ocean coincide in biomasses one order of magnitude higher than previous estimates. As mesopelagic fishes likely dominate the global fishes biomass even with the former estimate, our results indicate that the current global fishes biomass needs to be upgraded by one order of magnitude.

Primary production in the oligotrophic ocean is dominated by picoplankton ${ }^{24}$, which are not efficiently captured by copepods. It is therefore generally implied that the 'microbial loop' dominates the trophic web in oligotrophic areas, which therefore should support a lower transfer efficiency from PP to mesozooplankton, and hence to fishes, than more productive marine systems ${ }^{25}$. However, there is no direct evidence of a lower efficiency in less productive areas ${ }^{26}$. On the contrary some data suggest a tighter coupling between PP and grazing in oligotrophic seas ${ }^{19}$. Although a transfer efficiency of 0.1 between consecutive trophic levels is commonly assumed, values of 0.2 and higher are also used in trophic models of aquatic ecosystems ${ }^{21}$. Recent studies have shown that food-transfer efficiencies can vary several orders of magnitude, from less than 0.001 to significantly more than 0.1 (ref. 27).

The transfer efficiency between consecutive trophic levels implicit in our transfer efficiency estimates between TL1 and TL3 appears to be in conflict with the common wisdom that trophic chains in oligotrophic systems are less efficient than in productive shelf waters ${ }^{28}$ (generally considered to be 0.1 ). However, the transfer efficiency from PP to microzooplankton is probably

\section{Table 1 | Acoustic fishes biomass estimates.}

$s_{\mathrm{A}}$ estimate

Acoustic fishes biomass estimates

\begin{tabular}{|c|c|c|c|c|c|c|c|}
\hline & \multirow[t]{2}{*}{ Total $s_{A}$} & \multirow{2}{*}{$\begin{array}{c}\text { Average } \\
-34.6 \mathrm{db} \mathrm{kg}^{-1}\end{array}$} & \multirow{2}{*}{$\frac{\text { Median }}{-30.8 \mathbf{d b}^{\mathbf{k g}^{-1}}}$} & \multirow{2}{*}{$\frac{75 \%}{-28.4 \mathrm{db}_{\mathbf{k g}^{-1}}}$} & \multirow{2}{*}{$\begin{array}{c}25 \% \\
-42.2 \mathrm{db} \mathrm{kg}^{-1} \\
\end{array}$} & \multirow{2}{*}{$\begin{array}{c}\text { Max } \\
-26.8 \mathrm{db} \mathrm{kg}^{-1}\end{array}$} & \multirow{2}{*}{$\frac{\text { Min }}{-46.8 \mathrm{db} \mathrm{kg}^{-1}}$} \\
\hline & & & & & & & \\
\hline OLS: $s_{A}=2384.4^{\star} \ln (P P)-11678$ & $4.24 \mathrm{E}+17$ & 28,363 & 11,824 & 6,804 & 163,215 & 4,707 & 470,717 \\
\hline OLS: $\ln \left(s_{A}\right)=1.52^{\star} \ln (P P)-1.36$ & $4.70 \mathrm{E}+17$ & 31,449 & 13,110 & 7,544 & 180,972 & 5,219 & 521,930 \\
\hline GWR: $\ln \left(s_{A}\right)=1.36^{\star} \ln (P P)-0.2$ & $5.57 \mathrm{E}+17$ & 37,264 & 15,534 & 8,939 & 214,433 & 6,184 & 618,432 \\
\hline $\begin{array}{l}\text { GWR different equations for } \\
\text { PP above and below } 400^{\star}\end{array}$ & $4.38 \mathrm{E}+17$ & 29,321 & 12,223 & 7,034 & 168,725 & 4,866 & 486,607 \\
\hline $\begin{array}{l}\text { Cruise average } s_{A} \text { xocean surface } \\
\text { deeper } 1,000 \mathrm{~m}\end{array}$ & $4.14 \mathrm{E}+17$ & 27,427 & 11,433 & 6,579 & 157,826 & 4,552 & 455,176 \\
\hline
\end{tabular}


Table 2 | Target strength of mesopelagic fishes at survey frequencies.

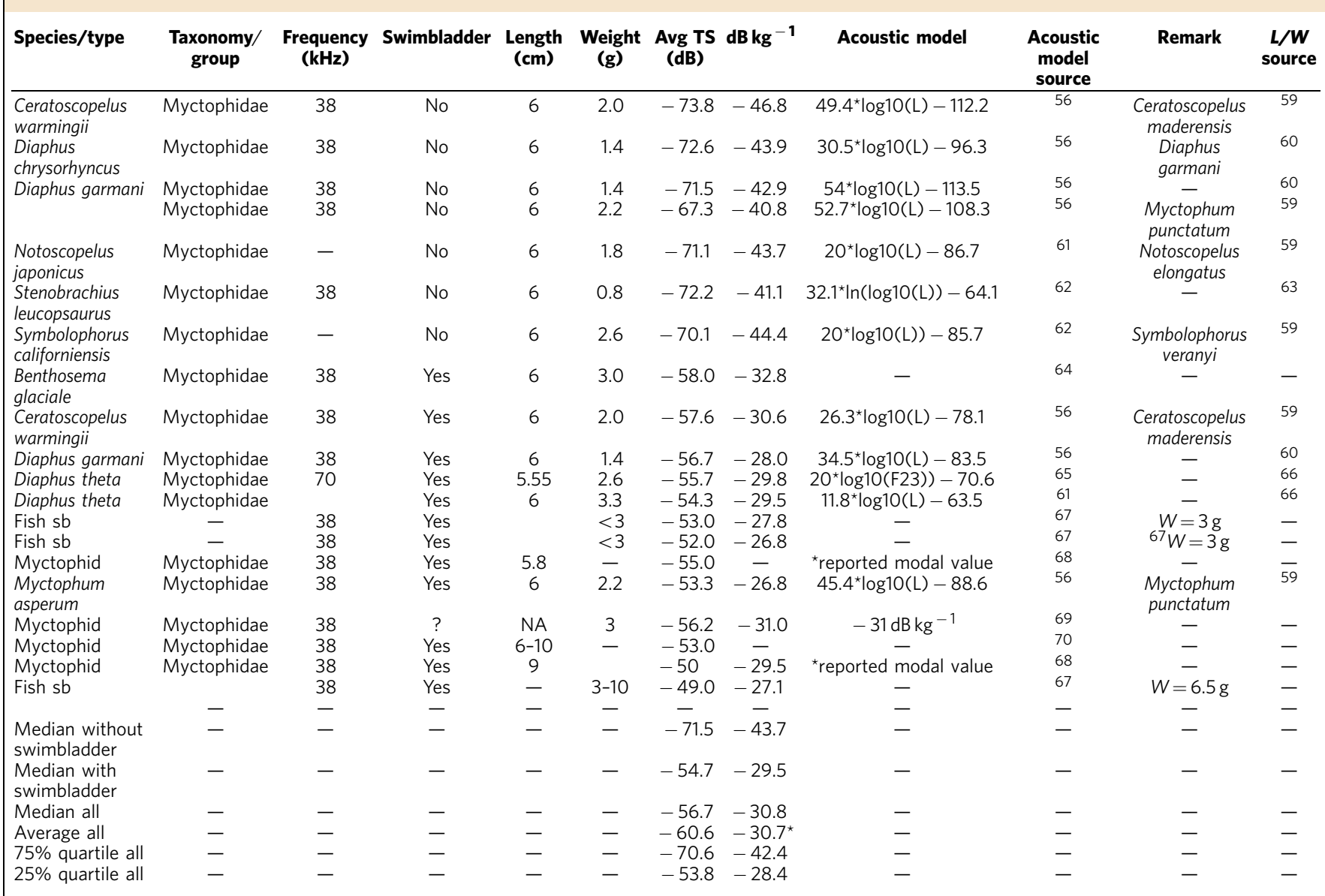

This table summarizes some recent target strength (TS) results for mesopelagic fishes. In cases where acoustic models exist, we have calculated TS at lengths close to $6 \mathrm{~cm}$, and we have used published regressions for length and weight $(L / W)$ relationships for the same or closely related species to estimate scattering from $\left.1 \mathrm{~kg}^{\text {biomass }(\mathrm{dB} \mathrm{kg}}{ }^{-1}\right)$.

${ }^{\star}$ Average value computed on the linear domain.

higher in warm areas of the ocean (oligotrophic zones) than in eutrophic areas, as grazing by heterotrophs is more tightly coupled to PP in warmer seas where heterotrophic metabolic rates increase faster than phototrophic rates relative to increases in temperature ${ }^{29}$. Further, the dominance of pico-sized primary producers in the oligotrophic ocean ${ }^{24}$ implies small losses due to sinking particles.

Mesopelagic fishes are visual predators feeding on mesozooplankton (TL3-4, see Methods). The trophic transfer efficiency from mesozooplankton to fishes is also probably higher in less productive and clear oceanic waters than in more productive and turbid shelf and coastal waters (Supplementary Table 2): clear water has a low beam attenuation coefficient $(c)$, which affords visual predators long sighting distances $(r)$, according to $r=k / c$, where $k$ is determined by the contrast and the contrast sensitivity of the prey and the predator, respectively ${ }^{30}$. The volume searched per unit time $(V)$ scales with $r^{2}$ for a cruising predator ${ }^{31}$ and is therefore effectively enhanced by decreased $c$ (that is, increased water clarity) according to $V \propto c^{-2}$ (Methods). In addition, clear water also has a low attenuation coefficient for downwelling irradiance $(K)$, which means that light penetrates deeper. Within the range allowed by deep hypoxic layers ${ }^{32}$, evidence suggests that vertical extension of fishes habitat $(H)$ scales according to $H \propto 1 / K$ (ref. 33). Thus, increased water clarity tends to increase both the short $(r)$ and the long $(H)$ range for visual foraging, thereby enhancing the transfer efficiency from mesozooplankton to mesopelagic fishes through more effective visual predation.
The quantity $c^{-2} K^{-1}$, which is proportional to the potential volume searched, is about one order of magnitude higher for clear oceanic water $\left(K=0.044 \mathrm{~m}^{-1}\right.$, the average in our study) than for turbid coastal waters with $K>0.1 \mathrm{~m}^{-1}$ (Supplementary Table 2). Thus, although increased PP in productive areas is likely to increase production at TL2 and TL3, it is also likely, beyond a certain point where high plankton biomass leads to high light attenuation and visual constraints become severe, to decrease the transfer efficiency between mesozooplankton and visual predators $^{34}$ relative to the transfer efficiency in clear waters at the oligotrophic ocean.

The evidence that mesopelagic fishes biomass, and consequently the total fishes biomass, is 10 -fold higher, or even more, than previously assumed has important implications for our understanding of the carbon fluxes in the ocean. A discrepancy in the estimates of export production using ${ }^{234} \mathrm{Th}:{ }^{238} \mathrm{U}$ disequilibria and shallow sediment traps has been systematically reported ${ }^{35}$. This discrepancy has generally been attributed to artifacts in the traps ${ }^{36}$ or to the episodic nature of the sinking events ${ }^{37}$. A comparison between reverse modelling estimated C export fluxes and sediment traps suggested that shallow traps $(<1,000 \mathrm{~m})$ underestimate the flux, whereas deep traps $(>1,000 \mathrm{~m})$ measured fluxes higher than the modelled ones ${ }^{8}$. An order of magnitude higher biomass of mesopelagic fishes might explain the difference. Mesopelagic fishes perform diel vertical migration, feeding at night in the upper layers (euphotic) and excreting and respiring at depth at day. This implies that 


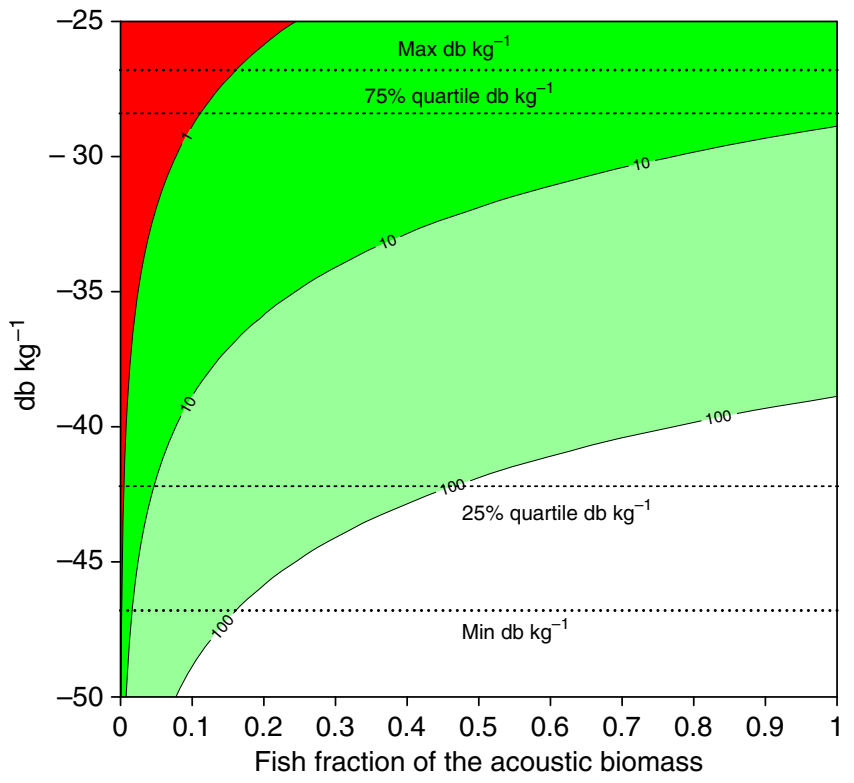

Figure 3 | Sensitivity analysis of the assumptions used to estimate biomass. Computations are based on the total backscatter estimated from the GWR regression (Table 1, 5.57E + 17), contours are the ratio of our estimate to 1,000 million tons. Quartiles, maximum and minimum values of the $\mathrm{db} /$ weight ratios found in literature are indicated by the dotted lines.

Table 3 | Fishes biomass Ecotroph estimates.

\begin{tabular}{lrrr}
\multirow{2}{*}{ Trophic efficiency between TL } & \multicolumn{3}{c}{$\% \mathbf{P P}$ to food chain } \\
\cline { 2 - 4 } & $\mathbf{7 0 \%}$ & $\mathbf{8 0} \%$ & $\mathbf{9 0 \%}$ \\
\hline $5 \%$ & 2,322 & 2,655 & 2,985 \\
$10 \%$ & 10,691 & 12,224 & 13,744 \\
$20 \%$ & 57,054 & 64,148 & 71,299 \\
\hline
\end{tabular}

Ecotroph fishes biomass estimates (millions of tons) between $40^{\circ} \mathrm{N}$ and $40^{\circ} \mathrm{S}$ as a function of the efficiency between trophic levels and the flux from PP to the first trophic level (TL).

mesopelagic fishes drive a vertical flux from the surface to the mesopelagic layer, bypassing the detection capacity of sediment traps. At the same time, by defaecating in deep waters, faeces produced with surface organic matter start sinking at depths of $\sim 500-700 \mathrm{~m}$, bypassing consumption in a large fraction of the water column and increasing the observed flux in deep traps. Basically, mesopelagic fishes accelerate the flux by actively transporting organic matter in the top layer of the water column, where most organic carbon is lost from the sedimentary particle flux.

Del Giorgio and Duarte ${ }^{39}$, using fishes production estimates derived from fisheries landings (mesopelagic fishes are not commercially fished), considered fishes respiration of little significance for the global ocean. However, a substantial revision of the mesopelagic fishes biomass upwards renders fishes respiration relevant. Assuming fishes respiration to be nine times production ${ }^{39}$ and half of it to happen in deep waters, up to $10 \%$ of the PP could be respired by mesopelagic fishes in deep waters (Table 4). This estimate is again in agreement with the local estimate in the northeast Pacific ${ }^{23}$. The estimate needs refinement in terms of time occupied and the respiration rates in deep layers (usually more than half of the day, but also at low temperatures), but indicates that, in deep layers, the sum of MFP and respiration is in the order of magnitude needed to explain the discrepancies between ${ }^{234} \mathrm{Th}:{ }^{238} \mathrm{U}$ disequilibria and shallow

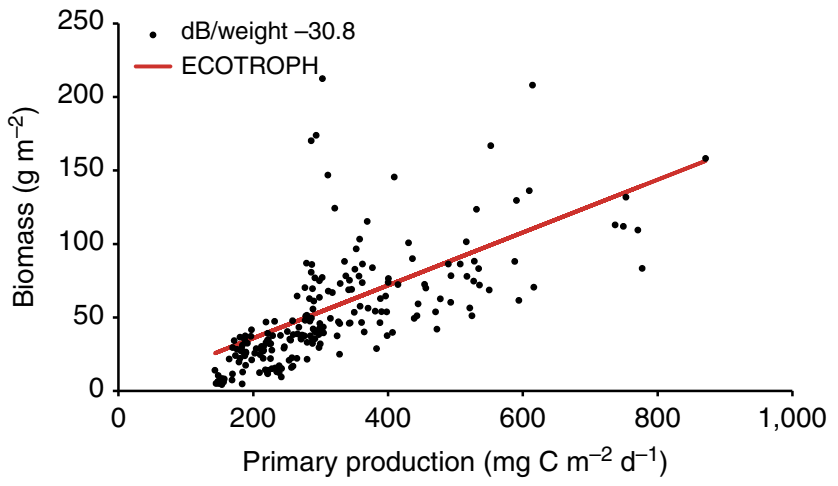

Figure 4 | Relation between PP and fish biomass. The relationship between PP (2010 annual average $\mathrm{mg} \mathrm{C}^{-2} \mathrm{~d}^{-1}$ ) and the estimated mesopelagic fishes biomass using the median $\mathrm{db}$ /weight ratio (black circles) and the ECOTROPH model with a transfer efficiency of 0.1 and considering that $90 \%$ of the PP enters the food web (red line). The regression equation of the acoustic biomass estimate against $\mathrm{PP}$ is mesopelagic fishes biomass $\left(\mathrm{g} \mathrm{m}^{-2}\right)=0.185 \mathrm{PP}\left(\mathrm{mg} \mathrm{C} \mathrm{m}^{-2} \mathrm{~d}^{-1}\right)-6.66$, $\left.r^{2}=0.46, P<0,001, n=209\right)$.

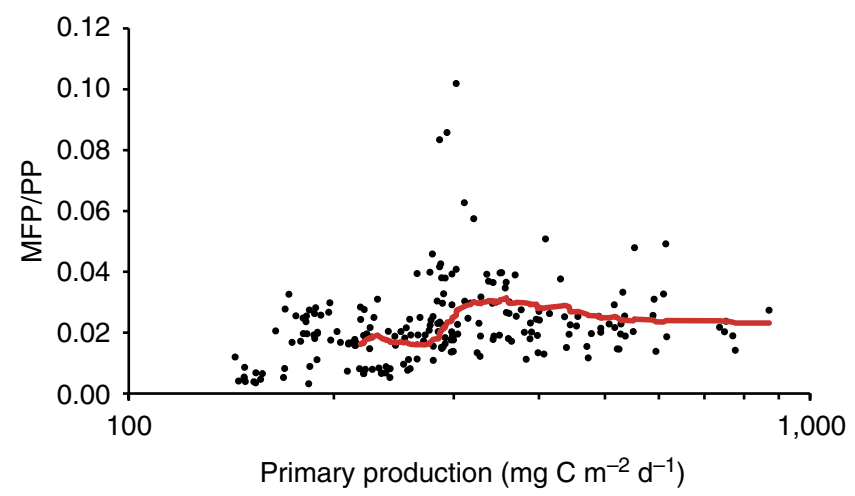

Figure 5 | Trophic efficiency. The estimated trophic efficiency from PP to MFP (the ratio of fishes production to PP) as a function of PP. The line is a 50 period running average for 50 contiguous estimates.

sediment traps. Moreover, the excretion in deep layers of materials ingested by mesopelagic fishes in the surface might partly explain the unexpectedly large microbial respiration in the deep ocean ${ }^{40}$.

Our results strengthen the previous claim that mesopelagic fishes are the most abundant fishes and, indeed, the most abundant vertebrates in the biosphere ${ }^{2}$. The results from the survey presented here suggest that trophic transfer efficiency from primary producers to fishes has been underestimated in the oligotrophic ocean, with the high transfer efficiency from primary producers to fishes associated with warm water temperatures and extreme water transparency, maximizing prey capture by visual predators. As many mesopelagic fishes, dominant in oceanic areas, are strong vertical migrators, feeding in the upper water column and excreting at depth, these results have important implications for the biogeochemical cycles of the ocean, as these animals provide trophic connectivity and transport organic carbon between the surface and the mesopelagic ocean, and could help explain existing discrepancies between flux estimates obtained by the ${ }^{234} \mathrm{Th}:{ }^{238} \mathrm{U}$ method and sediment traps ${ }^{35}$, as well as the unexpectedly large microbial respiration in deep water ${ }^{40}$.

Even with the current $10^{9}$ tons estimate mesopelagic fishes are considered to play a key role in the world's oceans as a link between plankton and top predators ${ }^{41}$ and in the oxygen 
Table 4 | Fish production and respiration estimates. PP, MFP and respiration estimates along the Malaspina transect.

\begin{tabular}{|c|c|c|c|c|c|}
\hline & $\begin{array}{l}\text { Primary production } \\
\left(\mathrm{gCm}^{-2} \mathrm{y}^{-1}\right)\end{array}$ & $\begin{array}{l}\text { Fish production median db/ } \\
\text { weight }\left(\mathrm{gC} \mathrm{m}^{-2} y^{-1}\right)\end{array}$ & $\begin{array}{l}\text { Fish production } 75 \% \mathrm{db} / \\
\text { weight }\left(\mathrm{g} \mathrm{C} \mathrm{m}^{-2} \mathrm{y}^{-1}\right)\end{array}$ & $\begin{array}{l}\text { Respiration median db/ } \\
\text { weight }\left(\mathrm{gCm}^{-2} \mathrm{y}^{-1}\right)\end{array}$ & $\begin{array}{l}\text { Respiration } 75 \% \mathrm{db} / \\
\text { weight }\left(\mathrm{g} \mathrm{C} \mathrm{m}^{-2} \mathrm{y}^{-1}\right)\end{array}$ \\
\hline Average (std) & $116(50)$ & $2.7(2)$ & $1.6(1.2)$ & $12.2(9)$ & $7.0(5.2)$ \\
\hline Max PP & 318.0 & 8.7 & 5.0 & 39.0 & 23.0 \\
\hline
\end{tabular}

depletion of the open ocean deep layers ${ }^{32}$. With the 10 -fold higher biomass found in this study and in recent local studies ${ }^{23}$ the conclusion about potential impacts of harvesting mesopelagic fishes extends to the global biogeochemical cycles. This finding calls for an effort to improve the accuracy of the estimates of the biomass and composition of the mesopelagic community. A more accurate estimate will require technological developments to increase the capturability of mesopelagic fishes and obtain detailed target strengths, as well as coordinated cruises across representative areas of the world ocean with sufficient resolution to address mesoscale structures.

\section{Methods}

Echosounder. Continuous acoustic measurements were made with a calibrated ${ }^{42}$ Simrad EK60 echosounder ( $7^{\circ}$ beam width), operating at a frequency of $38 \mathrm{kHz}$ and with a ping rate of 1 transmitted pulse per $2 \mathrm{~s}$. The data were stored for later analysis, carried out using the LSSS software ${ }^{43}$. The echosounder data were episodically affected by noise from various sources; consequently, prior to import into the LSSS software for post-processing, the data were subjected to a series of filters to remove bad data. These filters introduced a bias by removing the highest intensity data, however. The backscatter estimates, which are the basis of our biomass estimates, are therefore conservative.

The filters worked by comparing the integrated backscatter over a depth range with the background backscatter over the same depth range. Background intensities were detected using a median filter that was 400 pings wide, updated every 100 pings. Pings affected by attenuation were defined as pings with backscatter $>6 \mathrm{~dB}$ below the median in either of the depth ranges of 50-600 $\mathrm{m}$ or $600-1,000 \mathrm{~m}$. Periods with backscatter $>4 \mathrm{~dB}$ above background levels in the depth range $800-1,000 \mathrm{~m}$ were also marked. Pings tagged by these filters were excluded in further analyses. Lastly, a simple 9-point running median (horizontal) removed shorter irregular spikes. After manual scrutiny of the remaining data, the data were integrated in 2-minute-by-2-metre bins at a threshold of $-90 \mathrm{~dB}$. After integration in LSSS, data were imported into $\mathrm{R}^{44}$ for further analysis. Acoustic results were split into day, night and crepuscular data, using the function 'sunriset' from the 'maptools' package, with crepuscular periods defined as sunset/sunrise $\pm 1 \mathrm{~h}$.

To plot the echogram (Fig. 1b), the processed LSSS data were exported in 10-minute-by-1-metre bins to Matlab, where the nautical area scattering coefficient $\left(s_{\mathrm{A}}, \mathrm{m}^{2} \mathrm{nmi}^{-2}\right)$ was converted to volume backscattering strength $\left(S_{\mathrm{v}}, \mathrm{dB}\right.$ re $\left.1 \mathrm{~m}^{-1}\right)$. The daytime data were extracted $(2 \mathrm{~h}$ after sunrise and $2 \mathrm{~h}$ before sunset) and interpolated to remove the night-time gaps. Longer distances with missing or removed data (between cruise legs) were plotted as white.

Satellite data. The satellite data we used were all annual averages for the year 2010. Annual averages of PP for 2010 were generated by averaging monthly data for PP downloaded from the Ocean Productivity website (http://www.science. oregonstate.edu/ocean.productivity/index.php $)^{11}$. Cruise segments were then generated by combining all position fixes within a startpoint $\pm(8 \times 4.6) \mathrm{km}$ in north, south, east and west directions. The startpoint of the next segment was the first position registered outside this box. Alignment of in situ and satellite data was done by selecting the $64(8 \times 8$, size per bin $\sim 4.6 \times 4.6 \mathrm{~km})$ chlorophyll- $a$ bins along the segments that were closest to the midpoint (median position) within a cruise segment, with the added restriction that no chlorophyll- $a$ bin could be used twice. Values for these 64 bins, corresponding to an area of $\sim 37 \times 37 \mathrm{~km}$ were averaged. For the other satellite-derived measurements, the maximum and minimum positions of the chlorophyll- $a$ bins were used as boundaries for selection prior to calculation of the averages. Data from the conductivity temperature and depth (CTD) probe were aligned to cruise segments, and only CTD casts within a given cruise segment were used for a given segment.

Areas for biomass estimation. We used the PP-backscatter relation to estimate the mesopelagic biomass from satellite-derived PP data. We determined the biomass from the sum of the biomasses estimated from satellite-derived PP estimates using only areas where the bottom depth was $>1,000 \mathrm{~m}$.

We used the ETOPO1 data set (http://www.ngdc.noaa.gov/mgg/global/ global.html) to estimate the area. The bathymetry data set was translated down to a $10^{\prime}$ arc grid, and for every cell in the PP data set grid ( same spatial resolution not identical grids), we assigned the depth from the closest grid-point in the bathymetry data set. Primary production grid-points/cells with bottom depths shallower than $1,000 \mathrm{~m}$ were then excluded from our biomass estimation, as were areas north and south of 40 degrees north and south. This resulted in an area of 222.3 million $\mathrm{km}^{2}$.

Temperature data. The temperature data to estimate the MFP/biomass ratio (P/B) were obtained from the Malaspina Expedition CTD profiles. Profiles inside the PP boxes, or those closest to the boxes were used. As more data-points were available for daytime, we used the temperature at the daytime weighted mean depth (WMD) of the acoustic data. In areas where day- and night-time acoustic WMDs were available, the average difference between the daytime WMD temperature and the average temperature between day- and night-time WMD was $<0.1{ }^{\circ} \mathrm{C}$ (see Supplementary Table 3 ).

Modelling. The model ECOTROPH ${ }^{18}$ was run using the plugin incorporated to Ecopath with Ecosim ${ }^{45}$, (EwE, www.Ecopath.org) and the generic model Ocean Ecost as a basis. We used the average PP for the oceanic area deeper than $1,000 \mathrm{~m}$ between $40^{\circ} \mathrm{N}$ and $40^{\circ} \mathrm{S}\left(344 \mathrm{mg} \mathrm{C} \mathrm{m}^{-2} \mathrm{~d}^{-1}\right.$, http://www.science.oregonstate.edu/ ocean.productivity/index.php), considering a flux from PP to the trophic web of 70 , 80 and $90 \%$ (ref. 20), transfer efficiencies between trophic levels ranging from 0.05 to 0.2 (ref. 21) and a temperature of $9^{\circ} \mathrm{C}$ (see above).

ECOTROPH estimates biomass and production per trophic level (TL) in steps of 0.1 and we considered mesopelagic fishes as the main community between TL 3 and 3.5 in the open sea and biomass estimates are provided for that range. Mesopelagic fishes generally feed on zooplankton organisms such as copepods and euphausiids (www.fishbase.org). To determine the TL of mesopelagic fishes we used fishbase (www.fishbase.org) with searches for 'lanternfish' and 'bristlemouths' (myctophids and Cyclothone sp.). This yielded 96 and $15 \mathrm{TL}$ values for lanternfish and bristelmouths respectively. For lanternfish the TL ranged from 3 to 4.6, with an average of 3.2, mode of 3.1 and median of 3.2. For bristelmouths the TL ranged from 3 to 3.6, with an average of 3.3, mode of 3.5 and median of 3.3 .

Biomass transformations. For comparison, fishes production and PP were transformed from carbon into wet weight using a factor of 10:1 (ref. 21).

Statistics. Area scattering coefficient $\left(s_{\mathrm{A}}\right)$ was significantly correlated to PP. However, straight regression between the two factors $\left(s_{\mathrm{A}}=2374 \ln (\mathrm{PP})+11624\right)$ was limited by the heteroscedasticity of the data (Supplementary Fig. 1A). In principle heteroscedasticity does not affect ordinary least squares regression coefficient estimates, but can bias the significance estimates. Logarithmic transformation of the data $\left(\ln \left(s_{\mathrm{A}}\right)=1.52 \ln (\mathrm{PP})-1.36\right)$ eliminates heteroscedasticity (Supplementary Fig. 1B) but still presents spatial autocorrelation (Supplementary Fig. 2), that can increase type I errors ${ }^{12}$. GWR is a method to obtain regression parameters for each of the points in a spatial grid using the surrounding points weighted by distance. In spatial analysis GWR offers the advantage of extracting additional information at each location, as well as usually not being affected by spatial autocorrelation ${ }^{13}$. Here we carried a GWR regression on ln-transformed data using a bi-square spatial weighting function and a bandwidth of 4,130 units. The regression was performed using the Spatial Analysis in Macroecology software (SAM), ${ }^{46}$. Supplementary Table 1 presents the comparison of the three regressions in terms of parameters estimates, $r^{2}$ and Akaike coefficient. Supplementary Fig. 3 presents the spatial variations of the significance of the GWR slopes. The slopes were generally highly significant except in the Eastern Pacific, near the Humboldt current, where the layers below $100 \mathrm{~m}$ showed severe hypoxia (Supplementary Fig. 4). This suggests that the $s_{\mathrm{A}}-\mathrm{PP}$ relation is affected in that specific area either because severe hypoxic conditions influence the niche space, or because there is a strong external input of organic matter and local PP does not reflect the food conditions. Regardless, the type of regression used to estimate $s_{\mathrm{A}}$ from satellite PP has a limited effect on the overall biomass estimate (see Table 1).

The K- and c-effects on vision-based feeding habitats. Both the beam attenuation coefficient $\left(c, \mathrm{~m}^{-1}\right)$ and the downwelling irradiance attenuation coefficient $\left(K, \mathrm{~m}^{-1}\right)$ are affected by water clarity. We compared the quantity $c^{-1} K^{-2}$, which is proportional to a theoretical search volume, for clear oceanic and less clear coastal water (Supplementary Table 2). The quantity $c^{-1} K^{-2}$ has 
unit $\mathrm{m}^{3}$ and combines the effects that water clarity has on the short $(r$, the sighting distance) and the long ( $H$, the vertical extension of the habitat) range search ability of a vertically migrating visual predator.

The sighting distance is ${ }^{30}$ :

$$
r=k / c,
$$

where $k=\ln \left(C_{0} / C_{\min }\right), C_{0}$ is the inherent contrast of the prey, and $C_{\min }$ is the minimum contrast that the predator can detect ${ }^{30}$. The vision-based prey detection rate $(p)$ for a cruising predator tends to be proportional to $r^{2}$ (ref. 47), which in combination with Equation (1) gives:

$$
p \propto c^{-2} .
$$

A fish that migrates vertically has a larger potential feeding habitat than a fish that remains at the same depth. A greater area of migration also provides a larger potential feeding habitat ${ }^{48}$. Within the range allowed by oxygen levels ${ }^{32}$, for a fish with a certain light preference (isolume), the migration distance $(H, \mathrm{~m})$ scales with $K$ according to refs 33,47 :

$$
H \propto K^{-1} .
$$

The product of the right-hand side of Equations (1) and (2), $c^{-2} K^{-1}\left(\mathrm{~m}^{3}\right)$, combines the optical characteristics of the short- and the long-range search ability of a vertically migrating predator. We approximated this quantity, which is proportional to a theoretical search volume, for the average water clarity of the stations of the cruise and for hypothetical coastal waters with $K$-values of 0.10 and 0.15 , which are in the lower range of those reported in Table 6.2 in the study by Kirk and Light ${ }^{49}$. According to Supplementary Table 3, the estimate of this search volume is about one order of magnitude higher for the average Malaspina station than for the hypothetical coastal waters. This suggests that, in order for the vision-based prey detection rates to be equal, the prey concentration must be 10 times higher at the coastal location, assuming all other factors to be equal. This suggests that the high clarity of oceanic water enables efficient visual feeding at low prey concentrations.

Uncertainty analysis. Transforming acoustic measures into biomass involves uncertainty, dependent on the distribution of fishes sizes relative to acoustic wave lengths, on correctly ascribing the acoustic backscatter to fishes in scattering layers composed of different taxonomic groups as well as on the use of appropriate conversion factors from backscatter to biomass (TS values).

In order to assess the bias introduced through our non-standard postprocessing methods, we compared our results with results from standard acoustic post-processing in selected low-noise sections. Standard post-processing here refers to automated removal of noise spikes and background noise as implemented in the software LSSS, in addition to manual scrutiny of data and removal of periods where these automated filters did not eliminate all noise, or removed substantial portions of the data. Results are presented in Supplementary Figs 5 and 6 as a fraction of the difference between standard results and our results (only 200-800 $\mathrm{m}$ data, standard $s_{\mathrm{A}}$-filtered $s_{\mathrm{A}} /$ filtered $\left.s_{\mathrm{A}}\right)$. Fractions were averaged either per depth channel (Supplementary Fig. 6) or per time bin (Supplementary Fig. 7). Time-averaged results (Supplementary Fig. 7) suggest that there is a linear relationship between our estimates and standard estimates, with our estimates $~ 30-40 \%$ lower than standard estimates. The vertical bias profile (Supplementary Fig. 6) shows that there is a vertical influence on the bias, but that the bias appears almost constant at $30-40 \%$ in the $400-800$ metre depth range (suggesting the magnitude of underestimation for this depth range, encompassing most of the mesopelagic backscatter; $c f$. Supplementary Fig. 6). The bias is higher at depths shallower than $400 \mathrm{~m}$; it drops rapidly at depths lower than $800 \mathrm{~m}$, suggesting that there is no bias at $\sim 900 \mathrm{~m}$ and a negative bias deeper than this (that is, our estimates are higher than standard estimates at these depths).

The taxonomic composition of the organisms responsible for the mesopelagic backscatter along the path of this circumnavigation voyage is not known. Moreover, not all of the backscatter originates from fish. Early studies of the deep scattering layer concluded that larger crustaceans and in particular euphausiids were significant in the deep scattering layer ${ }^{50}$, but later studies showed that at the low frequencies used in these early studies, mesopelagic fish were the most significant scatterers, although with a possible contribution from gas-bearing siphonophores ${ }^{51}$. Larger crustaceans are relatively weak scatterers compared with organisms with air-inclusions at the frequency used in this study ${ }^{52}$, and therefore they probably made up a negligible proportion of the total backscatter at our frequency. Accordingly, recent studies from oceans around the world conclude that mesopelagic fish make up the majority of the backscatter' 914 yet proper 'ground truthing' is not possible due to the highly varying catch efficiency of sampling gear $^{7}$, which renders estimates derived from nets unreliable. Size of the fish is another potential issue. At $38 \mathrm{kHz}$ the acoustic wave length is $\sim 3.9 \mathrm{~cm}$. Individuals much smaller than the wavelength can be detected, particularly when occurring in high concentrations (although mesopelagic fish do not school). There is, however, an exponential decrease in acoustic backscatter with decreasing size in this socalled Rayleigh scattering region ${ }^{53}$. It is likely that a large part of the mesopelagic fish community is smaller than $3.9 \mathrm{~cm}$. This would lead to underestimating mesopelagic fish biomass, as fish in the Rayleigh domain would result in small $\mathrm{db} /$ weight ratios, except for individuals with a resonant swim bladder.
Resonance has the potential to result in a large bias of the estimate by directly affecting the acoustic results by up to 25 times $^{54}$. Swimbladder resonance may increase acoustic backscatter from small mesopelagic fish and organisms with air bubbles $^{55}$. However, although a certain level of resonance cannot be excluded, the data suggest that is not a major source of bias because (1) the ratio of paired day and night backscatter values is generally $<1,(2)$ if resonance was high and widespread the geographically weighted relation between $s_{\mathrm{A}}$ and PP should disappear and (3) the ecotroph model results agree well with the acoustic estimate.

Modelling and field studies suggest that the effects of resonance at $38 \mathrm{kHz}$ increase with depth ${ }^{9,56}$. Therefore, if the resonance effect was a major bias in our data set, we would expect the total night-time backscatter to be much lower than corresponding daytime values, because, on average, animals are distributed considerably closer to the surface at night, and thus producing lower resonance. We would also expect to observe high variability in the day/night ratio along the transect when going over different communities (fish species and sizes) with different resonance levels. We therefore compared day and night column $(10-1,000 \mathrm{~m})$ total backscatter values to check for the potential influence of resonance in our data. The ratio of paired day and night backscatter values (Supplementary Fig. 8 day $s_{\mathrm{A}} /$ night $s_{\mathrm{A}}$ ) shows that most of these values are $<1$ with low variability (average day/night ratio value 0.96 , s.d. 0.53 ). The vertical bias would tend to drive this ratio in the same direction as resonance, while migrations from deeper in the water column would oppose the trend. Our low ratios are inconsistent with resonance being a major factor. However, in one section along the cruise-track (East Pacific), the ratios appear to be higher (2-3), consistent with resonance playing a role. This is the same zone, with hypoxic waters at $100 \mathrm{~m}$ (see Supplementary Fig. 4), where the GWR is not significant. However, the biomass estimates in that area are not outliers in the general regression (Supplementary Fig. 9) or higher than that predicted by Ecotroph for the zone (Supplementary Fig. 10), which suggests that the day/night ratios $>1$ could be explained by factors other than an overestimation of the biomass. In this region, the night-time vertical profiles were particularly close to the surface, suggesting that a large proportion of the biomass actually migrates to the near-surface dead-zone of the echosounder, leading to a lower total night-time backscatter ${ }^{57}$. In any case the data from that limited area do not influence the estimations of global backscatter using different methods (regressions or average).

The spatial coherence of the GWR (GWR parameters and significance) is also a strong indication that resonance does not play a major role. Unless resonance was the same all along the transect (same community composition, sizes, depth distribution and migration patterns all around the world), resonance should eclipse the local relation between $s_{\mathrm{A}}$ and PP in areas where resonance was relevant. The GWR does not show such variability and the relation remains significant all along the transect, except for the North East Pacific area with hypoxic deep layers that also show higher day/night ratios (Supplementary Fig. 4).

Finally, the general estimate and the estimations along the transect agree with the Ecotroph model results using average parameters. The model is completely independent from acoustics estimates, based on PP and transfer efficiency. The agreement between the two independent approaches suggests that resonance is not a major source of bias in the acoustic data.

We use a range of literature $\mathrm{db} /$ weight ratio values to estimate biomass. This is a simplification that precludes exact estimation at each single point, but is largely to generate reliable average estimates, as the inaccuracies go both ways. A large portion of the backscatter from an individual fish normally originates from its gasfilled swimbladder ${ }^{52}$, but in mesopelagic fish reduced swimbladders or fat-filled swimbladders are common ${ }^{58}$ and have a strong effect on the TS of the fish. For instance, adults of some species of the genus Cyclothone may have gas-filled swimbladders, whereas only juveniles in other Cyclothone species have gas-filled swimbladders. There are other species of the same genus that never have gas-filled swimbladders ${ }^{58}$. Ground truthing in each area is not possible, but the $25-75 \%$ quartile range used in the estimates provided here should encompass the average TS value for the oceanic mesopelagic fish populations.

As our focus was mesopelagic fish, we did not include the backscatter from the upper $200 \mathrm{~m}$ layer (apart from the test on resonance). The additional fish biomass in the upper $200 \mathrm{~m}$ would contribute to a higher biomass estimate of total fish. The integrated $s_{\mathrm{A}}$ for the upper layer is on average $27 \%$ of the integrated value from $200-1,000 \mathrm{~m}$. However, if five areas with exceptionally high values were excluded, the average value would drop to $7 \%$ (Supplementary Fig. 11)

\section{References}

1. Marshall, N. B. Bathypelagic fishes as sound scatterers in the ocean. J. Mar. Res. 10, 1-17 (1951).

2. Nelson, J. S. Fishes of the World (Wiley, 2006).

3. Gjøsaeter, J. \& Kawaguchi, K. A review of the world resources of mesopelagic fish Vol. 193 (Bernan Press, 1980).

4. Lam, V. \& Pauly, D. Mapping the global biomass of mesopelagic fishes. Sea Around Us Project Newsletter 30, 4 (2005).

5. Tréguer, P., Legendre, L., Rivkin, R. T., Ragueneau, O. \& N, D. Ocean Biogeochemistry: The Role of Ocean Carbon Cycle in Global Change 145-156 (Springer, 2003).

6. Christensen, V. et al. Database-driven models of the world's Large Marine Ecosystems. Ecol. Modell. 220, 1984-1996 (2009) 
7. Pakhomov, E. \& Yamamura, O. Report of the Advisory Panel on Micronekton Sampling Inter-calibration Experiment (North Pacific Marine Science Organization (PICES), 2010).

8. Lara-Lopez, A. L., Davison, P. \& Koslow, J. A. Abundance and community composition of micronekton across a front off Southern California. J. Plank. Res. 34, 828-848 (2012).

9. Kloser, R. J., Ryan, T. E., Young, J. W. \& Lewis, M. E. Acoustic observations of micronekton fish on the scale of an ocean basin: potential and challenges. Ices J. Mar. Sci. 66, 998-1006 (2009).

10. Kaartvedt, S., Staby, A. \& Aksnes, D. L. Efficient trawl avoidance by mesopelagic fishes causes large underestimation of their biomass. Mar. Ecol. Prog. Ser. 456, 1-6 (2012).

11. Behrenfeld, M. J. \& Falkowski, P. G. Photosynthetic rates derived from satellite-based chlorophyll concentration. Limnol. Oceanogr. 42, 1-20 (1997).

12. Dormann, C. F. et al. Methods to account for spatial autocorrelation in the analysis of species distributional data: a review. Ecography 30, 609-628 (2007).

13. Fotheringham, A. S., Brunsdon, C. \& Charlton, M. Geographically weighted regression (Wiley, 2002).

14. Godo, O. R., Patel, R. \& Pedersen, G. Diel migration and swimbladder resonance of small fish: some implications for analyses of multifrequency echo data. Ices J. Mar. Sci. 66, 1143-1148 (2009).

15. Wilson, R. W. et al. Contribution of Fish to the Marine Inorganic Carbon Cycle. Science 323, 359-362 (2009).

16. Jennings, S. et al. Global-scale predictions of community and ecosystem properties from simple ecological theory. Proc. R. Soc. B Biol. Sci. 275, 1375-1383 (2008)

17. Tremblay-Boyer, L., Gascuel, D., Watson, R., Christensen, V. \& Pauly, D. Modelling the effects of fishing on the biomass of the world's oceans from 1950-2006. Mar. Ecol. Prog. Ser. 442, 169-185 (2011).

18. Gascuel, D. \& Pauly, D. EcoTroph: modelling marine ecosystem functioning and impact of fishing. Ecol. Modell. 220, 2885-2898 (2009).

19. Calbet, A. Mesozooplankton grazing effect on primary production: a global comparative analysis in marine ecosystems. Limnol. Oceanogr. 46, 1824-1830 (2001).

20. Calbet, A. \& Landry, M. R. Phytoplankton growth, microzooplankton grazing, and carbon cycling in marine systems. Limnol. Oceanogr. 49, 51-57 (2004).

21. Pauly, D. \& Christensen, V. Primary production required to sustain global fisheries. Nature 374, 255-257 (1995).

22. Gascuel, D., Morissette, L., Palomares, M. L. D. \& Christensen, V. Trophic flow kinetics in marine ecosystems: toward a theoretical approach to ecosystem functioning. Ecol. Modell. 217, 33-47 (2008).

23. Davison, P. C., Checkley, D. M., Kolslow, J. A. \& Barlow, J. Carbon export mediated by mesopelagic fishes in the northeast Pacific Ocean. Prog. Oceanogr. 116, 14-30 (2013)

24. Agawin, N. S. R., Duarte, C. M. \& Agusti, S. Nutrient and temperature control of the contribution of picoplankton to phytoplankton biomass and production. Limnol. Oceanogr. 45, 591-600 (2000).

25. Ryther, J. H. Photosynthesis and fish production in Sea. Science 166, 72-76 (1969).

26. San Martin, E. et al. Variation in the transfer of energy in marine plankton along a productivity gradient in the Atlantic Ocean. Limnol. Oceanogr. 51, 2084-2091 (2006).

27. Bonsall, M. B. \& Hassell, M. P. In: Theoretical Ecology Principles and Applications (eds May, R. M. \& McLean, A. R.) (Oxford University Press, 2007).

28. Jennings, S., Warr, K. J. \& Mackinson, S. Use of size-based production and stable isotope analyses to predict trophic transfer efficiencies and predator-prey body mass ratios in food webs. Mar. Ecol. Prog. Ser. 240, $11-20$ (2002).

29. Rose, J. M. \& Caron, D. A. Does low temperature constrain the growth rates of heterotrophic protists? Evidence and implications for algal blooms in cold waters. Limnol. Oceanogr. 52, 886-895 (2007).

30. Johnson, S. The Optics of Life (Princeton University Press, 2012)

31. Kiorboe, T. How zooplankton feed: mechanisms, traits and trade-offs. Biol. Rev. 86, 311-339 (2011)

32. Bianchi, D., Galbraith, E. D., Carozza, D. A., Mislan, K. \& Stock, C. A. Intensification of open-ocean oxygen depletion by vertically migrating animals. Nat. Geosci. 6, 545-548 (2013).

33. Aksnes, D. L. Evidence for visual constraints in large marine fish stocks. Limnol. Oceanogr. 52, 198-203 (2007).

34. Haraldsson, M., Tönnesson, K., Tiselius, P., Thingstad, T. F. \& Aksnes, D. L. Relationship between fish and jellyfish as a function of eutrophication and water clarity. Mar Ecol. Prog. Ser. 471, 73-85 (2012).

35. Buesseler, K. O. Do upper-ocean sediment traps provide an accurate record of particle-flux? Nature 353, 420-423 (1991).

36. Buesseler, K. O. et al. An assessment of the use of sediment traps for estimating upper ocean particle fluxes. J. Mar. Res. 65, 345-416 (2007).

37. Karl, D. M. et al. Building the long-term picture. Oceanography 14, 6-17 (2001).
38. Usbeck, R., Schlitzer, R., Fischer, G. \& Wefer, G. Particle fluxes in the ocean: comparison of sediment trap data with results from inverse modeling. J. Mar. Syst. 39, 167-183 (2003).

39. del Giorgio, P. A. \& Duarte, C. M. Respiration in the open ocean. Nature 420, 379-384 (2002).

40. Aristegui, J., Duarte, C. M., Gasol, J. M. \& Alonso-Saez, L. Active mesopelagic prokaryotes support high respiration in the subtropical northeast Atlantic Ocean. Geophys. Res. Lett. 32, L03608 (2005).

41. Smith, A. D. et al. Impacts of fishing low-trophic level species on marine ecosystems. Science 333, 1147-1150 (2011).

42. Foote, K., Knudsen, H., Vestnes, G., MacLennan, D. \& Simmonds, E. Calibration of Acoustic Instruments for Fish Density Estimation: a Practical Guide (International Council for the Exploration of the Sea, 1987).

43. Korneliussen, R. J., Heggelund, Y., Eliassen, I. K. \& Johansen, G. O. Acoustic species identification of schooling fish. Ices J. Mar. Sci. 66, 1111-1118 (2009).

44. Ihaka, R. \& Gentleman, R. R: a language for data analysis and graphics. J. Comput. Graph. Stat. 5, 299-314 (1996).

45. Christensen, V. \& Pauly, D. Ecopath-II-a software for balancing steady-state ecosystem models and calculating network characteristics. Ecol. Modell. 61, 169-185 (1992).

46. Rangel, T. F., Diniz, J. A. F. \& Bini, L. M. SAM: a comprehensive application for spatial analysis in macroecology. Ecography 33, 46-50 (2010).

47. Aksnes, D. L., Nejstgaard, J., Soedberg, E. \& Sornes, T. Optical control of fish and zooplankton populations. Limnol. Oceanogr. 49, 233-238 (2004).

48. Clark, C. W. \& Levy, D. A. Diel Vertical migrations by juvenile sockeye salmon and the antipredation window. Am. Nat. 131, 271-290 (1988).

49. Kirk, J. T. O. Light and Photosynthesis in Aquatic Ecosystems (Cambridge University Press, 1994).

50. Moore, H. B. The relation between the scattering layer and the Euphausiacea Biol. Bull. 99, 181-212 (1950).

51. Barham, E. G. Deep scattering layer migration and composition-observations from a diving saucer. Science 151, 1399-1403 (1966).

52. MacLennan, D. N. \& Simmonds, E. J. Fisheries Acoustics (Chapman \& Hall, 1992).

53. Horne, J. K. \& Jech, J. M. in Sounds in the Sea: From Ocean Acoustics to Acoustical Oceanography (ed Medwin, H.) 374-397 (Cambridge University Press, 2005).

54. Clay, C. S. \& Medwin, H. Acoustical Oceanography: Principles and Applications Vol. 4 (Wiley, 1977).

55. Benfield, M. C. et al. Distributions of physonect siphonulae in the Gulf of Maine and their potential as important sources of acoustic scattering. Can. J. Fish. Aquat. Sci. 60, 759-772 (2003).

56. Yasuma, H., Sawada, K., Takao, Y., Miyashita, K. \& Aoki, I. Swimbladder condition and target strength of myctophid fish in the temperate zone of the Northwest Pacific. Ices J. Mar. Sci. 67, 135-144 (2010).

57. O’Driscoll, R. L., Gauthier, S. \& Devine, J. A. Acoustic estimates of mesopelagic fish: as clear as day and night? Ices J. Mar. Sci. 66, 1310-1317 (2009).

58. Davison, P. The specific gravity of mesopelagic fish from the northeastern Pacific Ocean and its implications for acoustic backscatter. Ices J. Mar. Sci. 68, 2064-2074 (2011).

59. Fock, H. \& Ehrich, S. Deep-sea pelagic nekton biomass estimates in the North Atlantic: horizontal and vertical resolution of revised data from 1982 and 1983. J. Appl. Ichthyol. 26, 85-101 (2010).

60. Bernardes, R. \& Rossi-Wongtschowski, C. Length-weight relationship of small pelagic fish species of the southeast and South Brazilian Exclusive Economic Zone. Naga, the ICLARM Quarterly 23, 30-32 (2000).

61. Yasuma, H., Sawada, K., Olishima, T., Miyashita, K. \& Aoki, I. Target strength of mesopelagic lanternfishes (family Myctophidae) based on swimbladder morphology. Ices J. Mar. Sci. 60, 584-591 (2003).

62. Yasuma, H., Takao, Y., Sawada, K., Miyashita, K. \& Aoki, I. Target strength of the lanternfish, Stenobrachius leucopsarus (family Myctophidae), a fish without an airbladder, measured in the Bering Sea. Ices J. Mar. Sci. 63, 683-692 (2006).

63. Smoker, W. \& Pearcy, W. G. Growth and reproduction of the lanternfish Stenobrachius leucopsarus. J. Fish. Board Can. 27, 1265-1275 (1970).

64. Torgersen, T. \& Kaartvedt, S. In situ swimming behaviour of individual mesopelagic fish studied by split-beam echo target tracking. Ices J. Mar. Sci. 58, 346-354 (2001).

65. Sawada, K. et al. In situ and ex situ target strength measurement of mesopelagic lanternfish, Diaphus Theta (Family Myctophidae). J. Mar. Sci. Tech. Taiw. 19, 302-311 (2011).

66. Acuna, E. Biology of the myctophid fish, Diaphus theta Eigenmann and Eigenmann 1890, off the Oregon coast (Oregon State University, 1983).

67. Koslow, J. A., Kloser, R. J. \& Williams, A. Pelagic biomass and community structure over the mid-continental slope off southeastern Australia based upon acoustic and midwater trawl sampling. Mar. Ecol. Prog. Ser. 146, 21-35 (1997).

68. Kloser, R. J., Williams, A. \& Koslow, J. A. Problems with acoustic target strength measurements of a deepwater fish, orange roughy (Hoplostethus atlanticus, Collett). Ices J. Mar. Sci. 54, 60-71 (1997). 
69. Mamylov, V. S. Results of 'in situ' target strength measurements at $38 \mathrm{kHz}$ for major commercial species in the North Atlantic 3-18 (Murmansk, 1988).

70. Barr, R. \& Coombs, R. F. Target phase: an extra dimension for fish and plankton target identification. J. Acoust. Soc. Am. 118, 1358 (2005).

\section{Acknowledgements}

This research was conducted by the Malaspina 2010 Expedition project, funded by the Spanish Ministry of Economy and Competitiveness (Consolider-Ingenio 2010, CSD200800077). Additional financial support was provided by the Basque Country Government and by AZTI-Tecnalia. Thanks are due to all those who contributed to the success of the Malaspina 2010 Expedition. Thanks are due to D. Gascuel for his help and advice with ECOTROPH, L. Ibaibarriaga and A. Cozar for statistical advice and to V. Unkefer for editorial work on the manuscript.

\section{Authors contributions}

X.I., C.M.D. and S.K. conceived this project. U.M. and G.B. were in charge of calibration of the echosounders and data collection methodology. J.L.A., A.B., F.E., J.I.G.-G. and S.H.-L. ensured the quality of the data collection during the cruise. T.A.K. and A.R. analysed the data and contributed to interpretation and writing of the paper. S.A. contributed and interpreted the light attenuation data. X.I., S.K., T.A.K, A.R., D.L.A. and C.M.D. wrote and edited the paper. All authors discussed the results and commented on the manuscript.

\section{Additional information}

Supplementary Information accompanies this paper at http://www.nature.com/ naturecommunications

Competing financial interests: The authors declare no competing financial interests.

Reprints and permission information is available online at http://npg.nature.com/ reprintsandpermissions/

How to cite this article: Irigoien, X. et al. Large mesopelagic fishes biomass and trophic efficiency in the open ocean. Nat. Commun. 5:3271 doi: 10.1038/ncomms4271 (2014).

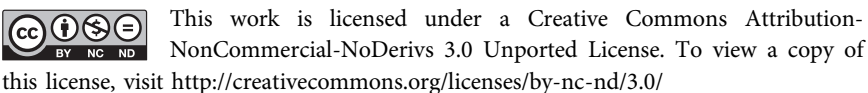

